\title{
A avaliação de políticas educacionais por meio da abordagem teórico-analítica do ciclo de políticas
}

\section{Evaluation of educational policies through the policy cycle theoretical-analytical approach}

\section{La evaluación de políticas educacionales por medio del abordaje teórico-analítico del ciclo de políticas}

\author{
Paulo Gomes Lima* \\ Ana Lúcia Marran**
}

\begin{abstract}
Resumo: Este artigo discute a importância da avaliação de políticas públicas para a área educacional, visto que se trata de um assunto recente em nosso país, uma vez que os primeiros registros sobre essa dimensão de investigação datam do início da década de 1980, a partir de Programas de Pós-Graduação em nível stricto sensu. A fundamentação epistemológica centrou-se nas contribuições da abordagem teórico-analítica do ciclo de políticas na perspectiva de Stephen Ball e seus colaboradores, segundo a qual existem contextos que são condicionados e condicionam as políticas públicas desde a abertura de sua agenda à implementação, daí um necessário instrumento avaliativo que explicite a consecução ou não dos objetivos esperados à luz dos contextos analisados. Para o campo educacional, o quadro de análise do ciclo de políticas de Ball, embora reúna consistência e coerência quanto à sua validade, radicalidade e rigorosidade nos estudos das avaliações das políticas, e em si mesmo, constitui-se como objeto de estudo; ainda é recente e os seus desdobramentos, bem como a natureza de suas limitações ainda estão para serem conhecidos no Brasil, por meio de estudos posteriores.
\end{abstract}

Palavras-chave: Abordagem do ciclo de políticas. Pesquisa educacional. Políticas educacionais.

\begin{abstract}
This article discusses the importance of evaluating public policies for education, once it is a recent subject in our country. The first records of this kind of investigation date back the 1980s, originated in stricto sensu post-graduation programs. The epistemological basis focuses on the contributions of the policy cycle theoreticalanalytical approach of Stephen Ball and his co-workers, according to whom there are contexts which are conditioned by and also influence the public policies from
\end{abstract}

\footnotetext{
* Professor do Programa de Pós-Graduação em Educação da Universidade Federal da Grande Dourados - UFGD. Docente lotado no Departamento de Ciências Humanas e Educação (DCHE) e do PPGED da UFSCar - campus Sorocaba. E-mail: <paulogl.lima@gmail.com>

** Professora da Universidade Estadual de Mato Grosso do Sul - UEMS. E-mail: < anamarran@yahoo.com.br>
} 
the opening of their agenda to their implementation. Thus, it is necessary to have an assessment tool which can reveal whether the objective of such policies is achieved or not, considering the contexts under analysis. Regarding the educational field, although Ball's policy cycle analysis framework is consistent and coherent in terms of validity, radicalism and rigor when applied to the study of policy evaluation, it also constitutes an object of study.

Keywords: Policy cycle approach. Educational research. Educational policies.

Resumen: Este artículo discute la importancia de la evaluación de políticas públicas para el área educacional, puesto que se trata de un tema reciente en nuestro país, una vez que los primeros registros sobre esa dimensión de investigación datan de inicios de la década de 1980, a partir de programas de Postgrado en nivel stricto sensu. La fundamentación epistemológica se centró en las contribuciones del abordaje teóricoanalítico del ciclo de políticas en la perspectiva de Stephen Ball y sus colaboradores, según la cual hay contextos que son condicionados y condicionan las políticas públicas desde la apertura de su agenda a su implementación, de ahí un necesario instrumento evaluativo que explicite la consecución o no de los objetivos esperados a la luz de los contextos analizados. Para el campo educacional, el cuadro de análisis del ciclo de políticas de Ball, aunque reúna consistencia y coherencia en cuanto a su validez, radicalidad y rigurosidad en los estudios de las evaluaciones de las políticas, y en si mismo, se constituye como objeto de estudio.

Palabras clave: Abordaje del ciclo de políticas. Investigación educacional. Políticas educacionales.

\section{Introdução}

Embora exista um número considerável de estudos recentes sobre a avaliação de políticas públicas (FIGUEIREDO; FIGUEIREDO, 1986; HOLANDA, 2003; LETICHEVSKY et al., 2005; BRANDÃO; SILVA; PALOS, 2005; FARIA, 2005; FIRME et al., 2009), observamos que quando se trata espeficamente de avaliação de impacto das políticas públicas para a educação, ainda não é comum a utilização no Brasil de quadros analíticos para a sua compreensão.

Consequentemente, há necessidade de evidenciar os eixos que orientam a abordagem do ciclo de políticas elaborado por Stephen Ball e seus colaboradores (BALL; BOWE, 1992; BOWE; BALL; GOLD, 1992; BALL, 2001) e que vem sendo estudada por autores brasileiros (MAINARDES, 2006; LOPES; MACEDO, 2011; MACEDO, 2006; LOPES, 2011).

A investigação científica de forma geral e, particularmente, na área educacional, solicita do pesquisador a apreensão de instrumentos e leituras epistemológicas suficientes de forma que lhe garanta o desvelamento do objeto, no mínimo, no âmbito da problemática constituída. Se a formulação 
do problema circunscreve-se à determinada área de conhecimento, como costumeiramente acontece com as pesquisas em profundidade, há que se identificar e possivelmente utilizar as dimensões categoriais que em maior ou menor medida contribuem para orientar ou mesmo encaminhar a leitura do objeto e as leituras dele derivadas. Nesse caso, sujeito, objeto e contexto tornamse elementos indispensáveis à triangulação das relações intrínsecas e extrínsecas da pesquisa, o que implica ser necessário analisar as relações de objetividadesubjetividade, tensões e encaminhamentos.

Nesse sentido, à medida que o pesquisador reúne tais elementos, selecionando recortes para se aproximar da leitura do real, assinalamos que o seu ponto de partida é a construção de um quadro de análise ou a utilização de uma abordagem teórico-analítica que lhe possibilite desenvolver a sua investigação científica centrada na tipologia do diálogo estabelecida entre os elementos próprios da pesquisa (epistemológicos axiológicos, gnoseológicos, ontológicos) e o estatuto conferido aos informantes no processo de construção do conhecimento (BRITO; LEONARDOS, 2001, p. 30).

$\mathrm{Na}$ área de políticas e gestão da educação, como lembram Azevedo e Aguiar (2001), os quadros de referência analíticos no Brasil ainda estão em construção, inclusive por conta da crise de paradigmas nas Ciências Sociais e Humanas e esta derivada dos processos de reestruturação e regulação políticas e econômicas. Nesta direção, Mainardes $(2009$, p. 5) chama atenção para o fato de que "[...] no Brasil, até o presente, são ainda raros os trabalhos que se propuseram a discutir abordagens metodológicas para a pesquisa sobre políticas públicas e educacionais", projeção esta que pode até constituir-se como desafio e objeto da área.

Hoje, na academia brasileira, as ideias do quadro de análise de Ball para o estudo das políticas públicas da educação vêm sendo objeto de estudo e aplicadas tendo em vista os condicionantes de suas orientações, processos históricos e inclinações do conceito e instrumentação da avaliação e qualidade da educação.

Em nível de exposição textual, este artigo está organizado em quatro seções que, reunidas, constituem-se o pano de fundo para a compreensão do quadro de análise do objeto, a saber, a) avaliação e política: definição e campo, b) avaliação política e avaliação de políticas, c) avaliação de políticas públicas e d) o ciclo de políticas: fundamentos e orientações.

\section{Avaliação e Política: definição e campo}

No caso brasileiro, a avaliação no campo das políticas públicas passa a ganhar notoriedade a partir do governo de Fernando Henrique Cardoso e das 
demandas do terceiro setor. Tal iniciativa, no entanto, não se preocupou mais pontuadamente na construção de uma cultura de avaliação, no amadurecimento dos instrumentos possíveis e formação de pessoal qualificado que pudessem não somente problematizar, mas reunir condições mais estratégicas de planejamento avaliativo que conferisse ao país consistência das políticas para determinado setor em curto, médio e longo prazo.

Entretanto, a orientação governamental centrada na administração gerenciada gerou demandas sobre este campo que até então não haviam sido levadas em consideração, mas com estas também se observava o ausentamento de um planejamento estratégico que as acompanhassem. A este respeito, Firme et al. (2009, p. 171) atestam que este quadro deflagrou vários desafios, dentre os quais: a) a falta de profissionais em sistemas de campo de avaliação, b) resistências de organizações, instituições e pessoas não dispostas a avaliar e usar os resultados das avaliações por motivos e interesses variados, c) ausência de uma rede entre os avaliadores e os interessados na avaliação, para estimular o desenvolvimento coletivo, além de d) escassas literaturas sobre avaliação em português e falta de cursos de formação para preparar adequadamente os avaliadores profissionais.

De acordo com Firme et al. (2009, p. 171), a falta de cultura de avaliação e de seu respectivo planejamento projetou pelo menos três dimensões para a realidade brasileira relacionadas com a política de avaliação que o país começara a desenvolver: 1) avaliação sem uma orientação política; 2) avaliação com uma política predeterminada desenhada por um pequeno grupo sem ampla e substancial discussão com o coletivo, não usando linguagem acessível a grupos específicos e, muitas vezes, falta de transparência e ampla difusão; 3) avaliação com uma política predeterminada concebida de forma aberta e coletiva e amplamente divulgados.

Embora se saiba que ainda não temos propriamente uma cultura de avaliação, pois esta certamente é fruto de planejamento e parâmetros bem definidos, onde qualidade e condições sociais são fatores intrínsecos, o Brasil ingressa no século XXI, ensaiando uma aproximação da terceira dimensão acima mencionada, "especialmente nas áreas educacionais e sociais", cujas representações dos movimentos coletivos se fazem sentir com maior vigor (FIRME et al., 2009, p. 173).

Assim como apontado por Firme et al. (2009), outros autores (HOLANDA, 2003; LETICHEVSKY et al., 2005; BRANDÃO; SILVA; PALOS, 2005), partindo do conceito elementar de avaliação, concordam que o âmbito do planejamento ou construção de uma cultura de avaliação das políticas públicas são imprescindíveis para a análise de seus impactos, validade de seus processos e execução. 
Holanda (2003) lembra que, de forma geral, avaliar significa julgar, medir, aferir ou analisar criticamente o mérito, o valor, a importância, a relevância ou a utilidade de algo, de alguém e até de um programa, assim carece de sistematização do instrumento e das demandas do imaginário social que se requer do âmbito ideal de qualidade. Letichevsky et al. (2005) sustentam que avaliar é um processo pelo qual se emite um juízo de valor sobre o que está sendo avaliado e acrescenta que isso se dá por meio de critérios estabelecidos pelo pesquisador, logo, se evidencia o planejamento como um patamar necessário para o seu desenvolvimento e análise dos resultados derivados dos processos empregados e logicamente a sua adequabilidade recíproca. Sob este olhar, Holanda (2003) complementa que a avaliação pode ser caracterizada como um procedimento sistemático de levantamento e análise de dados interessado em identificar os resultados, os impactos de uma ação e, além disso, verificar a sua relevância, sustentabilidade, eficiência e eficácia, sempre relacionando com os objetivos existentes em sua formulação.

Brandão; Silva e Palos (2005) destacam que a avaliação e a sua cultura como um processo de aprendizagem sistemático e intencional que um indivíduo, grupo ou organização se propõe a percorrer para aprofundar a sua compreensão sobre determinada intervenção social, por meio da elaboração e aplicação de critérios explícitos de investigação e análise, em um exercício compreensivo, prudente e confiável, com vistas a conhecer e julgar o mérito, a relevância e a qualidade de processos e resultados. $\mathrm{O}$ aperfeiçoamento do planejamento avaliativo ou a cultura de avaliação confere aos atores sociais condições de analisarem como suas políticas públicas estão sendo ou não, qual o seu grau de validade frente às demandas sociais identificadas ao longo de determinado tempo e intervenções. Daí a necessidade de maior discussão não somente sobre os instrumentos da avaliação em si, mas sobre quais critérios se assentam as políticas publicas, em caso específico, o papel que a educação tem no plano estratégico de desenvolvimento do país e as induções estabelecidas para a sua consecução.

Notadamente, o objetivo básico de qualquer avaliação é obter informações que sejam úteis, através da identificação das limitações, potencialidades e alternativas, de forma que possam contribuir para o processo de planejamento e formulação de determinada ação, de forma que possa ser aprimorada trazendo melhores resultados (HOLANDA, 2003), consequentemente, o seu campo de abrangência não se distancia de sua dimensão conceitual, isto é, o seu conceito e finalidade se afunilam e ganham consistência e delimitações de acordo com os setores ou recortes de seu objeto de estudo, como observaremos mais adiante no entrecruzamento de avaliação e políticas.

Dentre as inúmeras contribuições sobre definições e campo da política, destacamos que não pretendemos palmilhar ou esgotar quaisquer contribuições historicamente construídas, mesmo porque foge ao objetivo deste trabalho, pelo 
contrário, delimitamos a sua conceituação em nível mais estrito, isto é, em nível de política pública, caracterizada como:

[...] um curso de ação ou inação, escolhido por autoridades públicas para focalizar um problema, que é expressada no corpo das leis, regulamentos, decisões e ações de governo. A política pública está relacionada com as intenções que determinam as ações de um governo; com o que o governo escolhe fazer ou não fazer; com as decisões que têm como objetivo implementar programas para alcançar metas em uma determinada sociedade; com a luta de interesses entre o governo e sociedade; ou ainda, com atividades de governo, desenvolvidas por agentes públicos ou não, que têm uma influência na vida de cidadãos. (CAVALCANTI, 2007, p. 26).

Em sentido amplo, Palumbo (1994, p. 8) sustenta que a política consiste em "[...] um processo, ou uma série histórica de intenções, ações e comportamentos de muitos participantes". Não se limitando, somente, a uma lei, pois sua construção se dá junto ao desenvolvimento dos fatos, num fluxo de construção, reconstrução e adaptação. Em sentido mais estrito, quanto à política pública, ele vai defender que a "[...] sua manifestação visível é a estratégia adotada pelo governo para solucionar problemas públicos" (PALUMBO, 1994, p. 8), cada um dos problemas circunscritos a um corte estratégico de um país, como por exemplo, a educação, a saúde, a alimentação, o transporte, dentre outros setores poderiam ser caracterizadas como políticas públicas de corte social.

Ao estabelecer o marco de atendimento: normativo, operacional, se política de Estado ou programas de governo, é importante destacar que sua vigência pode ser temporalizada, por inúmeros fatores, dentre os quais, a sua inconsistência com a realidade dos atores sociais e condições materiais e de efetivação propriamente ditas. Com um olhar em nosso objeto, há que delinearmos a nossa compreensão sobre a concepção de política, como a delimitação de seu campo, como seguem.

Entendemos políticas públicas como uma ou conjunto de ações promovidas pelos governantes por meio de normatizações, que num primeiro momento podem partir de discussões coletivas, mas que a posteriori se materializam, seja por meio de legislações ou projetos, definidos com ou sem a participação popular, com interesse de atender a uma demanda.

E, ao se estabelecer no processo de implementação, poderá sofrer significativos impactos em nível de observações e reelaboração pelos agentes implementadores, podendo ou não conservar as mesmas estruturas, embora possa preservar os seus princípios. É oportuno destacar, por conseguinte, que para se estabelecer uma política pública de continuidade, ela terá que permanecer atuante independentemente do gestor em atuação. Nesse sentido, o que vai acentuar a 
sua validade, continuidade ou não são os processos de avaliação sobre o campo de determinada política, suas finalidades e resultados. Toda política deve sofrer um processo de avaliação para que possa ser aprimorada, pois no momento em que é pensada, não é possível prever acontecimentos favoráveis ou desfavoráveis que podem gerar a necessidade de se rever alguns pontos que foram previstos em sua elaboração.

A avaliação possibilita a ampliação de consciência sobre determinado programa ou projeto o que possibilita que escolhas e decisões maduras possam ser feitas, neste ínterim, uma avaliação requer autenticidade, curiosidade e rigor, o que nos coloca o desafio permanente de lidar com a incerteza, de sermos compreensivos com a realidade e de buscarmos, insistentemente, a construção de sujeitos (BRANDÃO; SILVA; PALOS, 2005).

Enfim, vale destacar Faria (2007), ao sustentar que independentemente do tipo de estudo, a avaliação tem como objetivo aprimorar a capacidade de oferecer subsídios adequados aos que estão sujeitos a determinada política, resumindo, a avaliação é parte crucial da formulação e implementação de políticas públicas contribuindo para seu aperfeiçoamento.

\section{Avaliação política e avaliação de políticas}

Embora a cunhagem terminológica de avaliação política e avaliação de políticas sejam similares, não se referem ao mesmo objeto, quando de seus propósitos e operacionalização instrumental, entretanto, não podemos afirmar que são dimensões excludentes na leitura avaliativa da temática política. Nesse contexto, faz sentido construirmos um quadro explanativo sobre sua diferenciação, assim como delimitarmos melhor avaliação de políticas como categoria inerente ao objeto dessa dissertação.

No primeiro caso, avaliação política consiste na análise e elucidação do critério ou critérios que fundamentam determinada política, os motivos que a tomam necessária. Assim, a avaliação política, se direciona para a medida do grau de consistência e coerência entre os objetivos sociais, os princípios de justiça, ética e legalidade e, claro, os meios necessários à sua materialização (FIGUEIREDO; FIGUEIREDO, 1986). Consequentemente, o propósito de avaliação política está associado à análise da dimensão de unidade de uma política pública, consoante a sua viabilidade, os eixos que dificultam ou obstaculizam o seu desenvolvimento. Além dessa dimensão, vale chamar a atenção para o fato de que a avaliação política contribui para se pensar elementos que se constituem o cerne das preocupações sociais e os encaminhamentos possíveis e tangíveis para a realidade dos grupos sociais. 
A esse quadro, Figueiredo e Figueiredo (1986) observam que algumas questões são fundamentais para se entender o campo da avaliação política, dentre as quais, figuram as seguintes: a) Quais são os propósitos que ela tem? b) Em que medida esses propósitos e objetivos respondem às demandas sociais? c) Que mecanismos foram acionados e qual a viabilidade funcional das estratégias adotadas - ou seja, qual a viabilidade de sucesso funcional? e d) Qual o potencial de efetividade se sua prioridade? Tais questões se apresentam como alguns exemplos do amplo espectro que a avaliação política deve dar conta, inclusive quando se leva em consideração os novos arranjos econômico-sociais e as demandas deles emanadas.

No segundo caso, a avaliação de políticas, além de verificar se os objetivos das políticas estão sendo atingidos, assim examina os processos pelos quais estão sendo implantados e os efeitos a ele atribuídos (BARRETO; PINTO, 2001). Tais políticas podem ser encaminhadas como planos, programas ou estratégias de intervenção sobre questões das demandas sociais.

Para Draibe (2001), a pesquisa de avaliação de políticas tem o objetivo de detectar dificuldades, obstáculos e propor medidas de correção, produzir recomendações visando à melhoria da qualidade do processo implementação e desempenho da política. Sob esse olhar, Cavalcanti (2007) complementa que outra faceta importante no processo de conhecimento dos resultados das políticas implementadas ou em andamento, por meio da avaliação de políticas, é analisar a sua validade para a realidade observada, isto é, se o desempenho, consequências, efeitos, impactos de ações e estratégias quando colocadas em práticas foram ou não eficientes e eficazes.

Vale destacar que no âmbito de pesquisas em avaliação de políticas públicas, a avaliação pode ser dividida em duas categorias, a saber, ex-ante e ex-post. Sendo que, a ex-ante é utilizada, principalmente, para os programas financiados por organismos multilaterais, com destaque aos voltados para infraestrutura econômica. Preocupa-se com a análise de custo benefício, do retorno do investimento previsto, entretanto, este tipo de avaliação não atende as necessidades dos estudos na área social, como a educação (LOBO, 2009).

A avaliação ex-post vai verificar os graus de eficiência e eficácia com que se está atendendo aos objetivos e a sua efetividade (resultados, impactos e efeitos) (DRAIBE, 2001). Lobo (2009), por sua vez, acrescenta que tipo de avaliação trabalha com impactos e processos, dos quais poderiam derivar algumas indagações: a) como a política específica foi proposta aos atores sociais finais? b) como esses atores trabalharam o seu desenvolvimento? c) quais foram as mudanças que se mostraram substanciais ou não? e d) tais políticas contribuíram efetivamente para o benefício coletivo e até que ponto? 
As distintas tipologias de análise que orientam a avaliação de políticas reúnem objetivos, critérios e modelos analíticos de maior ou menor complexidade, segundo as categorias delimitadas para apreciação, solicitando do pesquisador a dimensão procedimental pertinente (FIGUEIREDO; FIGUEIREDO, 1986). Nesse caso, a avaliação de políticas poderá compreender duas tipologias analíticas: avaliação de processos e avaliação de impactos.

A avaliação de processos tem por objetivo evidenciar o grau de eficácia e eficiência de determinada ação ou planejamento político como um todo, se o programa está sendo (ou foi) implementado de acordo com as diretrizes elaboradas para a sua execução e se o seu resultado atingirá (ou atingiu) os objetivos previstos. Nessa diretriz, o objetivo de sua aplicação é acompanhar e verificar se os propósitos, estratégias e execução do que foi estabelecido previamente estão sendo realizados, bem como o grau de aproveitamento ou validade da ação. Nesse sentido, importância da utilização dessa tipologia está no fato que não é possível prever todas as situações favoráveis ou não durante a elaboração de uma política e quando feita ao longo da implementação, possibilita o monitoramento dos processos responsáveis pela produção do resultado, permitindo controlar com antecipação o tamanho e a qualidade do efeito desejado. Os critérios de aferição do sucesso ou insucesso dessa tipologia entre eficácia e eficiência centram-se em três eixos: a) eficácia objetiva, b) eficácia funcional, administrativa e contábil e c) eficiência instrumental e política.

Por outro lado, a avaliação de impacto vai além e é bem mais complexa. Ela se preocupa aos efeitos do programa sobre o público submetido a ela e tem a intenção de estabelecer uma relação de causalidade entre a política e as alterações ocorridas naquele ambiente. (FIGUEIREDO; FIGUEIREDO, 1986), nesse sentido, a avaliação de impacto favorece outra leitura tendo como objeto de análise dos eventuais impactos implementados em determinado contexto e atores sociais.

Ampliando a explicitação da avaliação de impactos, delimitada pela implementação política como centralidade, Figueiredo e Figueiredo (1986, p. 113) acrescentam que os objetos a serem analisados podem compreender: a) impactos objetivos - mudanças quantitativas nas condições materiais, b) impactos subjetivos - mudanças subjetivas na percepção da população sobre o seu bem-estar ou nível de satisfação c) impactos substantivos nas condições de vida. A esse quadro, congrega-se a correlação de critérios de aferição (sucesso/fracasso) centrados na efetividade objetiva, subjetiva e substantiva da política em relação aos sujeitos, aos encaminhamentos realizados e contexto. 


\section{Avaliação de políticas públicas}

Os encaminhamentos das questões educacionais no Brasil, como também os de outros setores estratégicos, ocorrem em uma realidade complexa (diversidade cultural, extensão geográfica, desigualdade social), mobilizada por tensões e solicitações que exigem planejamento e avaliação constante no escopo Estado quanto à elaboração de políticas públicas. Nesse último caso, como forma de leitura da realidade das políticas públicas instituídas e de seus condicionantes materiais e ideais ${ }^{1}$ faz sentido o desenvolvimento de pesquisas acerca de sua avaliação, a despeito de que, como lembra Faria (2005, p. 101), “[...] a estruturação do campo de análise das políticas públicas ainda é bastante incipiente no Brasil [...]”.

Por isso, no processo de construção da cultura de avaliação de políticas públicas em que nos encontramos, as pesquisas acerca desse objeto não podem se reduzir a levantamento de dados ou mesmo a apreciação descritiva do status dessa ou daquela política pública, mas sem excluir esse encaminhamento, por conta da rigorosidade epistemológica, transformar dados em informações, permitindo diagnosticar uma situação e orientar ações, corrigindo deficiências ao propor soluções (PESTANA, 2009) e acrescentamos, ao levar em conta o imaginário social, observar os valores que fundamentam e podem contribuir para a ampliação ou universalização dos benefícios sociais. Uma mesma política pode causar impactos diversos, gerando mudanças nas condições da população atingida quer seja de ordem organizacional, de concepções político-sociais e até de qualidade de vida desse público (FIGUEIREDO; FIGUEIREDO, 1986).

A pesquisa sobre avaliação de políticas $^{2}$ tem destaque no Brasil a partir dos anos 80, no contexto do processo de transição política que traz consigo a necessidade de construção de políticas sociais que contemple toda a sociedade (CASTRO, 1989), surge como um processo de análise e acompanhamento da implementação de políticas, com vistas a orientar as tomadas de decisões para melhorar seus processos e relações sociais (SOUZA, 2009).

Ao abordar esse assunto, torna-se necessário recorrer a Frey (2000), que apresenta algumas definições da incipiente policy analysis. $\mathrm{O}$ autor conceitua polity

\footnotetext{
${ }^{1}$ Como observa Faria (2005, p. 100) “[...] a política da avaliação das políticas públicas está longe de se restringir a questões e disputas relativas à definição dos interesses prioritários e do escopo do Estado, posto que a avaliação pode também, por exemplo, ser elemento central na disputa eleitoral, no controle das interações inter-governamentais e na busca de acomodação de forças e de interesses no âmbito intraburocrático".

${ }^{2}$ Para Firme et al. (2009, p. 173, tradução nossa) a "Política de avaliação é significativa para avaliação e metaavaliação no sentido de garantir que todos tenham o mesmo entendimento sobre avaliação, sua finalidade e a forma como deve ser conduzida. Além disso, política é, em geral, uma declaração formal por escrito que é útil para guiar e determinar como uma avaliação deve ser implementada para que seja possível estabelecer um limite claro, evitando problemas éticos." A avaliação da política carece de da seleção das categorias a serem analisadas, de acordo com o propósito das políticas públicas, bem como de sistematização ao apresentar os resultados e serem propostos os encaminhamentos a partir de suas descobertas.
} 
como o momento em que se tratam as questões da estrutura política, sustenta que o objetivo da politics é compreender os processos de negociação da política e é a policy que evidencia o resultado concreto de uma política. Além disso, vale destacar, o policy cycle apresentado por Frey como um possível modelo para a análise das políticas públicas, que compreende a existência de fases comuns em todas as políticas, dentre as quais: a fase da formulação, da implementação e do controle dos impactos das políticas.

A avaliação é um instrumento importante para as tomadas de decisões, desta forma, na avaliação de políticas públicas deve se levar em conta o ambiente político no qual a política foi desenvolvida, as forças favoráveis e contrárias, assim como os seus princípios de eficiência, eficácia e efetividade (LOBO, 2009).

Como uma das fases do ciclo de políticas, a implementação corresponde à realização de ações previstas no processo de formulação da política, portanto, será a principal categoria que estará em evidência no quadro de análise de nosso objeto de pesquisa, visto que os sucessos e as dificuldades encontradas no processo de implementação podem resultar de questões envolvendo aspectos relacionados à capacidade institucional que quem a implementa, à natureza política da implementação e à resistência por grupos contrários a política (SILVA; MELO, 2000).

Nesse sentido, Frey (2000) afirma que as disputas políticas e as relações de poder, consequentemente, vão deixar marcas nas políticas desenvolvidas e implementadas, com isso, ao longo do tempo, todos os fatores condicionantes das políticas públicas podem sofrer alterações.

Para Draibe (2001), as pesquisas de avaliação de políticas públicas são importantes por identificar obstáculos e propor medidas com a intenção de melhorar a qualidade da implementação e do desempenho da política. Afirma que as políticas têm carne e osso, ou ainda, corpo e alma, pois são decididas e elaboradas por pessoas, são feitas para as pessoas e implementadas por pessoas, assim como avaliadas por elas. As pessoas decidem e atuam de acordo com seus valores, interesses e perspectivas o que vai influenciar todas suas ações frente a todas as fases da política.

Silva e Melo (2000, p. 11), ao tratarem da implementação de políticas destacam, que "[...] como a implementação implica em tomada de decisões, ela própria se constitui em fonte de informações para a formulação de políticas”. A partir do momento em que se toma o estudo dos impactos sentidos ou causados pela implementação como objeto de estudo, identificando os elementos geradores de sucesso/fracasso, encaminhamentos frágeis e outros substanciosos dos sujeitos contextuais, é possível ressignificar o conjunto das políticas públicas desenhadas ao quadro social, contribuindo para a geração de 
outros resultados e impactos e transformando em ações concretas as intenções daquelas (CAVALCANTI, 2007), uma vez que o seu grau de imersão indo além dos próprios dados, considerou o olhar de seus implementadores, de suas experiências vividas e de suas vozes, como aporte para o aprimoramento de questões não bem encaminhadas ou se encaminhadas com pontos dificultadores.

Segundo Arretche (2001), para o desenvolvimento da avaliação de implementação de uma política pública, é crucial saber se os agentes implementadores de fato a conhecem, caso contrário, eles elegerão outras referências na implementação; saber se eles aceitam os objetivos e as regras impostas pela política, pois caso discordem, poderão estabelecer suas próprias prioridades e, ainda, saber a condição institucional para a implementação da política, pois mesmo os implementadores conhecendo a política, sendo favorável aos seus objetivos e regras, se houver problemas institucionais, eles terão sérias dificuldades para a implementação e atendimento aos objetivos desejados. Consequentemente, o avaliador deve ter em mente que a implementação modifica o desenho original das políticas, pois acontece em ambiente que passa por contínua mutação e que os implementadores é que fazem a política, sendo fundamental verificar as condições em que a desenvolvem e sua disposição sobre a política em avaliação.

A avaliação de políticas públicas não é matéria fácil, entretanto, torna-se imprescindível o conhecimento da leitura de seus implementadores acerca dos eventos que ocorrem no processo de implementação como fontes para a identificação dos fatores que atuam sobre o seu contexto (DRAIBE, 2001). Nessa mesma direção, com as contribuições de Sabatier (1986), podemos dizer que a análise e avaliação do processo de implementação de uma política implicam a identificação e compreensão dos eventos e atividades que se seguem à formulação da política, isto é, a leitura dos condicionantes observados pelos atores sociais que estiveram envolvidos em sua operacionalização e, de forma mais pontuada, todas as informações coletadas podem ser encaminhadas para se pensar a elaboração de novas políticas públicas, o saneamento dos pontos frágeis ou a reestruturação estratégica de seu fortalecimento levando-se em conta a importância de sua eficiência, eficácia e efetividade ${ }^{3}$.

A partir do que foi apresentado, propomos aqui uma avaliação de política, ex-post que segundo Draibe (2001) pode ser realizada ao mesmo tempo ou após

\footnotetext{
${ }^{3}$ Vale lembrar que na pesquisa de políticas educacionais tem havido uma crescente resistência à separação de fases 'elaboração' e 'implementação' da política. A orientação mudou de ênfase sobre as intenções de política das autoridades centrais a nível macro para incorporar uma análise das práticas de política, os efeitos e consequências a nível micro. Por exemplo, Cibulka (1994, p. 111) reconheceu que "agora reconhecemos que implementadores têm um papel fundamental na política explícita, não apenas um técnico" [...] e Fitz e Halpin (1994) argumentam que deve-se buscar uma abordagem equilibrada entre o poder central para divulgar a política e a capacidade dos profissionais a interpretar as políticas, em vez de simplesmente executá-los (VIDOVICH, 2001).
} 
a implementação de uma política com a intenção de verificar seus resultados e efeitos, o que desenvolvida pela avaliação de impacto, como opção analítica à luz da abordagem do ciclo de políticas, elaborado por Ball e seus colaboradores (BALL; BOWE, 1992; BALL, 2001, 2006; BOWE; BALL; GOLD, 1992). Para tanto, é necessário contextualizarmos a compreensão sobre os fundamentos e orientações da abordagem do ciclo de políticas, enriquecida com leituras complementares da literatura especializada sobre a temática (VIDOVICH, 2001; MAINARDES, 2006, 2007; MAINARDES; MARCONDES, 2009; BORBOREMA, 2008; AROSA, 2008; AMARAL, 2010; SHIROMA; CAMPOS; GARCIA, 2005).

\section{O ciclo de políticas: fundamentos e orientações}

A abordagem do ciclo de políticas (policy cycle approach), formulada pelo sociólogo inglês Stephen Ball e seus colaboradores, se tornou um referencial analítico muito utilizado, pois comporta uma análise crítica e contextualizada de programas e políticas de educação, considerando os contextos macrossociais de sua elaboração até a sua implementação no contexto da prática e os seus resultados correspondentes (MAINARDES, 2006).

Em entrevista concedida a Mainardes e Marcondes (2009, p. 305), o sociólogo inglês Stephen Ball enfatiza que a abordagem do ciclo de políticas é um método, uma maneira de pesquisar e teorizar as políticas, sem nenhum interesse em explica-las, dito de outra maneira, "O ciclo de políticas não tem a intenção de ser uma descrição das políticas, é uma maneira de pensar as políticas e saber como são feitas, usando alguns conceitos diferentes [...] o de atuação." (MAINARDES; MARCONDES, 2009, p. 305, grifo dos autores). Outro ponto, intrinsecamente relacionado a esse, é o fato de que as políticas não dizem exatamente o que deve ser feito, elas criam circunstâncias que vão ser analisadas e executadas de acordo com a interpretação de seus leitores (BALL, 2006).

Na década de 1990, Ball (1994, p. 10) destacava que para uma política ter legitimidade e efetivar-se como tal, é necessário conhecer como os indivíduos e grupos interpretam-na e a ressignificam ou não para a sua realidade, neste sentido, a política pública compreende "[...] tanto texto e ação, palavras e ações, o que é promulgado, bem como o que se pretende".

Embora seja concebido um documento de origem que contemple o texto da política pública advindo das várias instâncias de discussão de um determinado país, o governante ou o Estado não devem imputar-lhe um caráter prescritivo e determinístico, com o risco de invalidar a consecução de sua finalidade e desdobramento, pois a política destina-se a uma totalidade social ou a um segmento referendado por ela, solicitando que a dimensão de sua explicitude seja evidenciada. 
A capacidade de efetivação da implementação de uma política está centrada na condição de leitura e devolutivas dos contextos para os quais foram elaboradas e da dialogicidade com os atores sociais ou implementadores em relação à sua ressignificação, consequentemente, não se pode colocar à margem o entendimento de que as políticas resultam de uma bricolagem de conceitos e decisões globais e locais, na qual um influencia o outro numa relação mútua. Para Ball (2001, p. 122),

Há uma tensão, que percorre todas as variedades e análise de políticas, entre, de um lado, a necessidade de atender as particularidades locais do processo de elaboração e de execução de políticas e, de outro, a necessidade de se levar em conta os padrões gerais a as aparentes convergências entre localidades ou aquilo que elas têm em comum.

A abordagem do ciclo de políticas utiliza os diversos contextos políticos relacionando os acontecimentos em âmbito global com o local e vice-versa, analisando o quanto um influencia nas decisões políticas do outro, o que pode gerar mudanças no desenvolvimento de suas ações. Assim, essa abordagem:

[...] destaca a natureza complexa e controversa da política educacional, enfatiza os processos micropolíticos e a ação dos profissionais que lidam com as políticas no nível local e indica a necessidade de se articularem os processos macro e micro na análise de políticas educacionais. É importante destacar desde o princípio que este referencial teórico-analítico não é estático, mas dinâmico e flexível. (MAINARDES, 2007, p. 27).

Através da abordagem do ciclo de políticas, é possível enfocar a análise da política considerando a formação do discurso da política e da interpretação dada a ela por pessoas que irão relacionar os textos da política para a sua aplicação prática. Vale destacar que existem vários níveis de elaboração de discursos e em cada nível, uma rede própria de poderes e significados (BORBOREMA, 2008). Isso significa que as falas ou os discursos dos atores a serem considerados devem levar em consideração a sua vinculação com a política pública e, portanto, a compreensão dos:

[...] discursos sobre o que pode ser dito e pensado, mas também sobre quem pode falar, quando e com que autoridade. Discursos estabelecem relações de significados sociais, que constituem as relações de subjetividade e poder. Discursos são práticas que sistematicamente formam os objetos de que eles falam [...] Na medida em que os discursos são constituídos por exclusões, bem como inclusões, por aquilo que não é como o que pode ser dito, destacam-se na relação antagônica com outros discursos (BALL, 1990, p. 2).

Nesse sentido, Mainardes (2006, p. 50) sustenta que "[...] isso envolve identificar processos de resistências, acomodações, subterfúgios e conformismo 
dentro e entre as arenas da prática, e o delineamento de conflitos e disparidades entre os discursos nessas arenas". Isso não excetua o olhar sobre o planejamento das políticas públicas para a área das ciências humanas e em seu cerne a educação, visto que " $[. .$.$] o desenvolvimento epistemológico nas ciências humanas,$ como a educação, funciona politicamente e é intimamente imbricado no gerenciamento prático dos problemas sociais e políticos" (BALL, 2006, p. 18), o que não pode prescindir de uma avaliação de suas dimensões.

A abordagem do ciclo de políticas, como caminho possível da avaliação de políticas, foi proposta originalmente por Ball e Bowe (1992) compreendendo três contextos principais, isto é, dimensões específicas na leitura do objeto, a saber: o contexto de influência, o contexto da produção de texto e o contexto da prática. Esses contextos se relacionam entre si e cada um tem suas características próprias, como lugares e grupos de interesses, envolvendo disputas e embates (BOWE; BALL; GOLD, 1992).

O primeiro contexto é o contexto de influência ${ }^{4}$ : este é o momento em que as políticas públicas são iniciadas e os discursos políticos são construídos. É nesse contexto que grupos de interesse disputam para influenciar a definição das finalidades da política e seus significados. Nesse contexto, atuam as redes sociais dentro e em torno de partidos políticos, do governo e do processo legislativo (MAINARDES, 2006). Complementando, Eugênio (2009) destaca que também podem ser analisadas nesse contexto a influências da circulação internacional de ideias, dos organismos internacionais e dos grupos e indivíduos que vendem suas soluções no mercado político e acadêmico por meio de periódicos, livros, conferências, entre outros. É também nesse espaço que os conceitos adquirem legitimidade e é constituído o discurso que lhe dá embasamento (MAINARDES, 2006; AROSA, 2008).

Para Ball e Bowe (1992), este primeiro contexto tem uma relação simbiótica com o segundo, o contexto da produção de texto $0^{5}$, no entanto, é não evidente ou

\footnotetext{
${ }^{4}$ Para Vidovich (2001), embora não haja uma listagem de pontos que deem conta de explorar todas as particularidades do contexto de influência observadas pelos implementadores, algumas que poderiam facilitar o entendimento do contexto poderiam ser elaboradas a partir do eixo central: Que ou quais forças são observadas que influenciam ou influenciaram a implentação de determinada política? e a posteriori a essa questão geradora, seriam acrescentadas outras com as seguintes provocações: a) Há influências internacionais sendo exercidas? Se sim, tais influências são geradas por quais países? b) Como são materializadas as influências globais e internacionais? c) Em que medida as influências de nível globais e internacionais são mediadas dentro do Estado-nação? d) Quais são as condições ideológicas, econômicas e políticas vigentes? e) Quem é a elite política e os interesses que representam? f) Que outros grupos de interesse estão tentando influenciar a política? g) Quais interesses são mais/menos poderoso e por quê? h) Este contexto de influência perdurou por quanto tempo e em que medida influenciou a política antes de ela ser elaborada? (Tradução nossa).

${ }^{5}$ Neste contexto, o eixo norteador de avaliação da política pública centra-se em identificar as forças que atuaram na produção do texto científico, agregando-se a partir daí, questões acessórias tais como: a) Quando começou a construção do texto de política e 'porque agora' ou neste momento?; b) Quais grupos de interesse (partes interessadas) foram representados na produção do texto da política e quais foram os excluídos?; c)
} 
simples, pois enquanto o contexto de influência está relacionado com interesses e ideologias, os textos políticos estão apresentados com a linguagem do interesse da população, pois o texto político representa a política. Esse contexto engloba a produção de diversos textos como os documentos legais, ofícios, discursos, entre outros.

Os textos políticos resultam de disputas e acordos, pois os grupos atuantes dos diferentes locais da produção de textos competem entre si para controlar as representações da política (BOWE; BALL; GOLD, 1992). O que gera uma elaboração de texto que tem consequências que são vivenciadas no contexto da prática. Tais textos não são, necessariamente, coerentes e claros e podem até mesmo ser contraditórios.

Para Ball e Bowe (1992), a política não é feita e finalizada no momento legislativo e os textos precisam ser lidos com relação ao tempo e ao local específico de sua produção. Corroborando com isso, Arosa (2008) traz sua contribuição sustentando que considerar a política como texto, significa observar as diferentes possibilidades de se produzirem intervenções textual, gerando leituras múltiplas, devido à grande quantidade de pessoas que as lê, bem como os resultados das influências, intenções e negociações envolvendo o reconhecimento, ou não, de algumas vozes. Assim, "embora caracterizado com um tom prescritivo [...] os textos da política dão margem a interpretações e reinterpretações, gerando, como consequência, atribuições de significados e de sentidos diversos em um mesmo termo.” (SHIROMA; CAMPOS; GARCIA, 2005, p. 431).

Ball (2001) enfatiza que os textos políticos são o resultado de uma série de negociações, de várias influências e diversos interesses, pois durante o processo de construção, algumas vozes são legitimadas e ouvidas, outras não. A constituição das políticas se dá, em sua maioria, por ensaios de tentativas e erros que são reelaborados, modificados por meio de complexos processos de influências, de discursos e de recriação no contexto da prática.

Quais processos foram usados para construir o texto de política e por quê?; d) Quais compromissos foram feitos entre os grupos de interesse diferentes (partes interessadas) e como eles foram alcançados? ; e) que interesses as políticas se propõem a cumprir?; f) Quais são os discursos dominantes do texto da política e os discursos que são excluídos?; g) Qual é a intenção ou propósito da política?; h) Na proposta da política elaborada, há agendas escondidas ou não explícitas?; i) Quais valores são refletidos na política?; j) Quais são as questões que constituem o foco da política, estas se referem a agendas de política global e internacional?; k) Quais são os principais conceitos ou conceitos-chave da política proposta?; l) Qual é o formato/tipologia de política adotado e por quê? m) Qual é a linguagem da política e por quê?; n) Há incoerências e contradições no texto política?; o) Quem é o público-alvo do texto política?; p) O texto da política é acessível ou compreensível para o público?; q) As etapas para 'implementação' são claramente definidas e integrantes do texto de política?; r) O processo de implementação terá recursos ou será financiado? s) Existe um mecanismo especificado para avaliar a política? Estas questões não esgotam as leituras possíveis do contexto da produção do texto da política, entretanto, constituem-se como elementos de reflexão que, em maior ou menor medida, poderão contribuir para melhor sua melhor compreensão (VIDOVICH, 2001). 
Sobre o contexto da prática ${ }^{6}$, terceiro momento da abordagem do ciclo de políticas, Ball e Bowe (1992) afirmam que é o momento em que a política está sujeita à interpretação, em que podem ser relidas, reelaboradas, recriadas e onde são produzidos seus efeitos e consequências geradoras de alterações e transformações importantes para a área ou setor a que se destina. Para estes autores, o contexto da prática constitui-se como o tendão de Aquiles, isto é, ao dialogar com a leitura e o imaginário dos implementadores, constata-se que as políticas não são simplesmente colocadas em prática conforme está no texto, elas podem ser interpretadas de diferentes formas e, então, podem ser reconstruídas. Logo, não se pode negar o processo de ressignificação ou reinterpretação dos profissionais que exercem um papel ativo no processo de implementação das políticas, no caso específico para a sua dimensão de trabalho, como por exemplo, é o caso das políticas públicas para a educação.

Da mesma forma, Amaral (2010) destaca que esse contexto vem despertar para o entendimento que as políticas são interpretadas e recriadas, logo, observa-se que uma mesma política pode ser desenvolvida de várias maneiras em diferentes contextos da prática, devido aos diversos entendimentos dos sujeitos sociais.

As orientações existentes nos documentos de política educacional são interpretadas e adaptadas à determinada realidade que será aplicada, antes de ser implementadas, sendo assim, não é imediatamente assimilável ou aplicável (SHIROMA; CAMPOS; GARCIA, 2005).

A abordagem do ciclo de políticas entende que o profissional do contexto da prática também é um autor das políticas educacionais, pois sua interpretação sobre o texto irá definir sua prática, nesse sentido, não são simplesmente executores de algo já estabelecido por outrem.

\footnotetext{
${ }^{6}$ Vidovich (2001) destaca que uma questão necessária à compreensão desse contexto ancora-se em saber "quais foram as forças ou efeitos que atuaram sobre o contexto da implementação prática da política? A essas seguem: a) Esta política está sendo implementada numa variedade de contextos?; b) Como se diferenciam as práticas de políticas para a realidade que foi desenhada ?; c) São evidentes as influências globais/internacionais no contexto da prática da política local ?; d) Quem pode ter acesso e quem efetivamente a acessa?; e) A interpretação da política é aberta e clara para os implementadores?; e) Como a política foi recebida pelos implementadores?; f) Quem colocou a política em prática e por quê?; g) Quais processos foram usados para colocar a política em prática e por quê?; h) Em que medida a política é resistida (ativa ou passivamente)?; i) A resistência é coletiva ou individual?; j) Em que medida a política é transformada em cada uma das instituições no processo de implementação? k) O processo de implementação das políticas, bem como os seus efeitos foram previstos?; 1) Os implementadores das políticas fazem parte do contexto para o qual ela foi projetada?; m) Os implementadores são capazes de responder e de se reunir prontamente para atender as necessidades localizadas no domínio do contexto da prática política?; n) Quais foram as consequências ou efeitos não intencionais no processo de implementação da política?; o) Qual é o impacto da política em diferentes agrupamentos localizados com base na classe, gênero, etnia, ruralidade e deficiência?; p) Existem vencedores ou perdedores no contexto da prática ou processo de implementação da política?
} 
Sobre essa questão, Borborema (2008) sustenta que tal releitura acaba sendo inevitável, acontecendo naturalmente, pois cada profissional tem formas de trabalhar diferenciadas, priorizando valores e saberes que julgam essenciais e direcionam sua prática por diferentes interpretações da política.

Os sujeitos que estudam os textos não os leem de forma ingênua, eles vêm com suas bagagens cheias de experiências, valores e propósitos. Políticas serão interpretadas diferentemente de um para outro, visto que cada tem sua própria bagagem e interesses diversos. O ponto-chave é que quem elabora os textos políticos não tem controle sobre o significado e eles vão ter, então, trechos podem ser rejeitados ou absorvidos, ignorados, mal entendidos ou não. Lembrando que podem utilizar somente o que lhes interessa, mas uma ou outra interpretação vai ser predominante mesmo com alguns desvios. (BOWE; BALL; GOLD, 1992).

Em 1994, no livro Education reform: a critical and post-structural approach, Ball ampliou o estudo da abordagem do ciclo de políticas acrescentando outros dois contextos ao referencial original: o contexto dos resultados (efeitos) e o contexto da estratégia política. O contexto dos resultados importa-se com questões de justiça, igualdade e liberdade individual. Pressupõe que as políticas têm efeitos e não tão somente resultados, defendendo que elas devem ser analisadas em termos do seu impacto e das interações com desigualdades existentes (MAINARDES, 2006). O contexto da estratégia política, "[...] envolve a identificação de um conjunto de atividades sociais e políticas necessárias para lidar com as desigualdades criadas ou reproduzidas pela política investigada". (MAINARDES, 2006, p. 60).

No entanto, vale destacar que em entrevista no ano de 2009, o próprio Stephen Ball disse ter repensado esses dois últimos contextos e afirmou que não é útil separá-los, ele entende que o contexto dos resultados deve ser incluído no da prática e o contexto da estratégia política no da influência. Assim, sustenta que "[...] em grande parte, os resultados são extensão da prática, [...] o contexto da ação política, na realidade, pertence ao contexto da influência, porque é parte do ciclo do processo através do qual as políticas são mudadas, ou podem ser mudadas." (MAINARDES; MARCONDES, 2009, p. 306).

Para Ball, a avaliação de políticas por meio do ciclo é um método que define como as políticas são feitas e atuam em distintos contextos, o que para a área educacional poderá trazer contribuições quanto aos elementos envolvidos na elaboração de uma política específica, como é desdobrada e em sua dimensão da prática como é vivida e ressignificada pelos atores sociais. Ora, como afirmam Ball em entrevista concedida a Mainardes e Marcondes (2009, p. 306) em meio a uma arena de disputas, evidenciam-se relações de poder, interesses e inclinações no processo de elaboração e atuação das políticas. Assim, podemos inferir que, como recurso ou instrumento de análise de políticas públicas nessa perspectiva, 
traz para a área educacional um rico método de avaliação que poderá certamente ser aperfeiçoado pelo amadurecimento de novas sensibilidades que se fazem nas relações vividas pelo homem e por ele superadas ao longo do tempo.

\section{Considerações finais}

Como destacam Ball e Mainardes (2011, p. 14), embora uma vez construídas, as políticas não são fixas e imutáveis, visto que são sujeitas a interpretações, a traduções e, acrescenta-se, de ressignificações efetuadas pelos sujeitos ao longo de distintas leituras, mas devem ser compreendidas, mesmo que de forma não acabada, como voltadas às respostas aos problemas da prática. Daí ser necessário compreender em que contextos se dão, quais significados e interesses estão presentes dentre outros.

Para o campo educacional, o quadro de análise do ciclo de políticas reúne consistência e coerência quanto à sua validade, radicalidade e rigorosidade no estudo das avaliações das políticas. A essa perspectiva, Power (2011) observa que o entendimento de estudos em políticas e práticas educacionais, em específico, a partir dos macrocontextos, orienta uma leitura mais criteriosa, revelando os movimentos, intenções e encaminhamentos acerca do objeto.

Santos e Azevedo (2009) chamam de estudos críticos a perspectiva que analisa as políticas implementadas, que denunciam suas fragilidades, incoerências teórico-práticas e avanços e alternativas acerca de novas orientações tendo em vista o aprimoramento da qualidade social desejada. A discussão e utilização desse quadro de análise para as políticas educacionais no Brasil certamente apresenta-se como enriquecedor instrumento, bem como por si mesmo, um objeto de estudo, cujos desdobramentos ainda estão por acontecer.

\section{Referências}

AMARAL, J. C. S. A política de gestão da Educação Básica na rede estadual de ensino do Rio Grande do Sul (2007-2010): o fortalecimento da gestão gerencial. 2010. 211 f. Tese (Doutorado em Educação) - Universidade Federal do Rio Grande do Sul, Porto Alegre, 2010.

AROSA, D. V. S. A construção do discurso oficial sobre a avaliação da aprendizagem escolar nas políticas públicas em educação no município de Queimados/RJ entre os anos de 2001 e 2007. 2008. 158 f. Dissertação (Mestrado em Educação) - Universidade Federal do Estado do Rio de Janeiro, Rio de Janeiro, 2008.

ARRETCHE, M. T. Uma contribuição para fazermos avaliações menos ingênuas. In: BARREIRA, M. C. R. N.; CARVALHO, M. C. B. (Orgs.). Tendências e perspectivas na avaliação de políticas e programas sociais. São Paulo: IEE/PUC-SP, 2001. p. 43-56.

AZEVEDO, J. M. L.; AGUIAR, M. A. A produção do conhecimento sobre a política 
educacional no Brasil: um olhar a partir da ANPED. Educação \& Sociedade, Campinas, v. 22, n. 77, p. 49-70, dez. 2001. DOI: 10.1590/S0101-73302001000400004

BALL, S. J. Introducing Monsieur Foucault. In: BALL, S. J. (Ed.). Foucault and education. London: Routledge, 1990. p. 1-8.

Education reform: a critical and post-structural approach. Buckingham and Philadelphia: Open University Press, 1994.

Cidadania Global, consumo e política educacional. In: SILVA, L. H. da (Org.). A escola Cidadã no contexto da globalização. 5. ed. Petrópolis: Vozes, 2001. p. 121-137.

Sociologia das políticas educacionais e pesquisa crítico-social: uma revisão pessoal das políticas educacionais e da pesquisa em política educacional. Currículo sem Fronteiras, v. 6, n. 2, p. 10-32, jul./dez. 2006.

BALL, S. J.; BOWE, R. Subject departments and the "implementation" of National Curriculum policy: an overview of the issues. Journal of Curriculum Studies, London, v. 24, n. 2, p. 97-115, 1992. DOI: 10.1080/0022027920240201

BALL, S. J.; MAINARDES, J. (Orgs.). Políticas educacionais: questões e dilemas. São Paulo: Cortez, 2011.

BOWE, R.; BALL, S.; GOLD, A. Reforming education \& changing schools: case studies in policy sociology. London: Routledge, 1992.

BARRETTO, E. S. S.; PINTO, R. P. Avaliação de programas educacionais: indagações metodológicas e disseminação de resultados. In: BARREIRA, M. C. R. N.; CARVALHO, M. C. B. (Orgs.). Tendências e perspectivas na avaliação de políticas e programas sociais. São Paulo: IEE/PUC-SP, 2001. p. 101-126.

BORBOREMA, C. D. L. Política de ciclos na perspectiva do ciclo de políticas: interpretações e recontextualizações curriculares na rede municipal de educação de Niterói/ RJ. 2008. 175 f. Dissertação (Mestrado em Educação) - Universidade Federal do Rio de Janeiro, Rio de Janeiro, 2008.

BRANDÃO, D. B.; SILVA, R. R.; PALOS, C. M. C. Da construção de capacidade avaliatória em iniciativas sociais: algumas reflexões. Ensaio: Avaliação e Políticas Públicas em Educação, Rio de Janeiro, v. 13, n. 48, p. 361-374, jul./set. 2005. DOI: 10.1590/S0104-40362005000300006

BRITO, A. X. de.; LEONARDOS, A. C. A identidade das pesquisas qualitativas. Cadernos de Pesquisa, São Paulo, n. 113, p. 7-38, jul. 2001. DOI: 10.1590/S0100-15742001000200001

CASTRO, M. H. G. Avaliação de programas e políticas sociais. Caderno de Pesquisa, Campinas, n. 12, p. 1-5, 1989.

CAVALCANTI, P. A. Sistematizando e comparando os enfoques de avaliação e de análise de políticas públicas: uma contribuição para a área educacional. 2007. 315 f. Tese (Doutorado em Educação) - Universidade Estadual de Campinas, Campinas, 2007.

CIBULKA, J. G. Policy analysis and the study of the politics of education. Journal of Education Policy, n. 9, p. 105-125, 1994. DOI: 10.1080/0268093940090511

DRAIBE, S. M. Avaliação de implementação: esboço de uma metodologia de trabalho em políticas públicas. In: BARREIRA, M. C. R. N.; CARVALHO, M. C. B. (Orgs.). Tendências 
e perspectivas na avaliação de políticas e programas sociais. São Paulo: IEE/PUC-SP, 2001. p. 13-42.

EUGÊNIO, B. G. Políticas curriculares para o Ensino Médio no Estado da Bahia: permeabilidades entre contextos e a cultura da escola. 2009. 207 f. Tese (Doutorado em Educação) - Universidade Estadual de Campinas, Campinas, 2009.

FARIA, C. A. P. A política de avaliação de políticas públicas. Revista Brasileira de Ciências Sociais, São Paulo, v. 20, n. 59, p. 97-110, out. 2005. DOI: 10.1590/S0102-69092005000300007

FARIA, R. M. Avaliação de programas sociais: evoluções e tendências. In: RICO, E. M. (Org.). Avaliação de políticas sociais: uma questão em debate. 5. ed. Cortez: Instituto de estudos especiais, 2007. p. 41-50.

FIGUEIREDO, M. F.; FIGUEIREDO, A. M. C. Avaliação política e avaliação de políticas: um quadro de referência teórica. Análise e Conjuntura, Belo Horizonte, v. 3, n. 1, p. 107127, set./dez. 1986.

FIRME, T. P. et al. Evaluation culture and evaluation policy as guides to practice: reflections on the Brazilian experience. Ensaio: Avaliação e Políticas Públicas em Educação, Rio de Janeiro, v. 17, n. 62, p. 169-180, jan./mar. 2009. DOI: 10.1590/S0104-40362009000100009

FREY, K. Políticas públicas: um debate conceitual e reflexões referentes à política da análise de políticas públicas no Brasil. Planejamento e Políticas Públicas, n. 21, p. 211-259, jun. 2000 .

HOLANDA, A. N. C. Avaliação de políticas públicas: conceitos básicos, o caso do ProInfo e a experiência brasileira. In: CONGRESO INTERNACIONAL DEL CLAD SOBRE LA REFORMA DEL ESTADO Y DE LA ADMINISTRACIÓN PÚBLICA, 8., 2003, Panamá. Anais... Panamá, 2003. p. 28-31.

LETICHEVSKY, A. C.; VELLASCO, M. M. B. R.; TANSCHEIT, R.; SOUZA, R. C. La categoría precisión en la meta-evaluación: aspectos prácticos y teóricos en un nuevo enfoque. Ensaio: Avaliação e Políticas Públicas em Educação, Rio de Janeiro, v. 13, n. 47, p. 255-268, abr./jun. 2005. DOI: 10.1590/S0104-40362005000200008

LOBO, T. Avaliação de processos e impactos em programas sociais: algumas questões para reflexão. In: RICO, E. M. (Org.). Avaliação de políticas sociais: uma questão em debate. 6. ed. São Paulo: Cortez: Instituto de Estudos Especiais, 2009. p. 75-84.

LOPES, A. C. Políticas de currículo: questões teórico-metodológicas. In: LOPES, A. C.; DIAS, R. E.; ABREU, R. G. de. (Org.). Discursos nas políticas de currículo. Rio de Janeiro: Quartet, 2011. p. 19-45.

LOPES, A. C.; MACEDO, E. Contribuições de Stephen Ball para o estudo de políticas de currículo. In: BALL, S. J.; MAINARDES, J. (Orgs.). Políticas Educacionais: questões e dilemas. São Paulo: Cortez, 2011. p. 249-283.

MACEDO, E. A diferença nos PCN do Ensino Fundamental. In: LOPES, C. A.; MACEDO, E. (Orgs.). Políticas de currículo em múltiplos contextos. São Paulo: Cortez, 2006. p. 159-186.

MAINARDES, J. Abordagem do ciclo de políticas: uma contribuição para a análise de políticas educacionais. Educação \& Sociedade, Campinas, v. 27, n. 94, p. 47-69, jan./abr. 2006. DOI: 10.1590/S0101-73302006000100003 
Reinterpretando os ciclos de aprendizagem. São Paulo: Cortez, 2007.

Análise de políticas educacionais: breves considerações teórico-metodológicas. Contrapontos, Itajaí, v. 9, n. 1, p. 4-16, jan./abr. 2009.

MAINARDES, J.; MARCONDES, M. I. Entrevista com Stephen Ball: um diálogo sobre justiça social, pesquisa e política educacional. Educação \& Sociedade, Campinas, v. 30, n. 106, p. 303-318, jan./abr. 2009. DOI: 10.1590/S0101-73302009000100015

PALUMBO, D. J. Public policy in America: government in action. 2. ed. San Diego: Harcourt Brace \& Company, 1994. p. 8-29.

PESTANA, M. I. G. S. Avaliação educacional - o sistema nacional de avaliação da Educação Básica. In: RICO, E. M. (Org.). Avaliação de políticas sociais: uma questão em debate. 6. ed. São Paulo: Cortez: Instituto de Estudos Especiais, 2009. p. 53-63.

POWER, S. O detalhe e o macrocontexto: o uso da teoria centrada no Estado para explicar práticas e políticas educacionais. In: BALL, S. J.; MAINARDES, J. (Orgs.). Políticas educacionais: questões e dilemas. São Paulo: Cortez, 2011. p. 54-77.

SABATIER, P. Top-down and bottom-up approaches to implementation research. Journal of Public Policy, v. 6, n. 1, p. 21-48, jan. 1986. DOI: 10.1017/S0143814X00003846

SANTOS, A. L. F.; AZEVEDO, J. M. L. A pós-graduação no Brasil, a pesquisa em educação e os estudos sobre a política educacional. Revista Brasileira de Educação, Rio de Janeiro, v. 14, n. 42, p. 534-605, set./dez. 2009. DOI: 10.1590/S1413-24782009000300010

SHIROMA, E. O.; CAMPOS, R. F.; GARCIA, R. M. C. Decifrar textos para compreender a política: subsídios teórico-metodológicos para análise de documentos. Perspectiva, Florianópolis, v. 23, n. 2, p. 427-446, jul./dez. 2005.

SILVA, P. L. B.; MELO, M. A. B. O processo de implementação de políticas públicas no Brasil: características e determinantes da avaliação de programas e projetos. Caderno n. 48. Núcleo de estudos de políticas públicas/Unicamp, 2000.

SOUZA, L. G. Avaliação de políticas educacionais: contexto e conceitos em busca da avaliação pública. In: LORDÊLO, J. A. C.; DAZZANI, M. V. (Orgs.). Avaliação Educacional: desatando e reatando nós. Salvador: EDUFBA, 2009. p. 17-30.

VIDOVICH, L. A conceptual framework for analysis of education policy and practices. In: AUSTRALIAN ASSOCIATION FOR RESEARCH IN EDUCATION CONFERENCE, 2001, Fremantle. Anais... Fremantle: AARE, 2001.

Recebido em 06/07/2012

Versão final recebida em 11/03/2013

Aceito em 19/03/2013 